\title{
Pemberian aromaterapi lavender terhadap lama persalinan kala II pada ibu primipara
}

\section{Giving lavender aromatherapy to the second stage of labor in primipara mother's}

\author{
Asri Noviyanti ${ }^{*}$, Jasmi $^{2}$ \\ ${ }^{1,2}$ Poltekkes Kemenkes Palembang, Palembang, Sumatera Selatan, Indonesia \\ 1'noviyantiasri4@gmail.com*; ${ }^{2}$ jasmi@ poltekkespalembang.ac.id \\ *corresponding author \\ Tanggal Submisi: 16 Maret 2021, Tanggal Penerimaan: 8 Juni 2021
}

\begin{abstract}
Abstrak
Persalinan merupakan suatu proses yang alamiah. Secara fisiologis, pada ibu bersalin akan terjadi kontraksi yang menyebabkan penipisan dan pembukaan serviks. Hal ini akan menyebabkan ibu merasakan nyeri. Peningkatan nyeri persalinan dihubungkan dengan kecemasan berlebihan karena tegangan otot meningkat sehingga menyebabkan efektivitas kontraksi uterus berkurang, bahkan memperpanjang proses persalinan kala II. Pemberian aromaterapi lavender merupakan salah satu metode nonfarmakologi untuk merelaksasi ibu bersalin dan mampu mempersingkat kala II persalinan. Tujuan penelitian ini adalah untuk mengetahui perbedaan pemberian aromaterapi lavender pada ibu bersalin kala II. Metode penelitian ini adalah penelitian observasional quasy eksperimental dengan metode two group post test only design pada $60 \mathrm{ibu}$ bersalin. Analisis data menggunakan uji mann whitney Hasil penelitian diperoleh bahwa pemberian aromaterapi lavender pada persalinan II dapat meningkatkan relaksasi ibu dan mempercepat durasi persalinan kala II.
\end{abstract}

Kata kunci: aromaterapi; lavender; persalinan; primipara

\begin{abstract}
Childbirth is a natural process. Physiologically, the mother will experience contractions that cause cervical thinning and opening. This will cause the mother to feel pain. Increased labor pain is associated with excessive anxiety because the increased muscle tension causes the effectiveness of uterine contractions to decrease, and even prolongs the second stage of labor. Lavender aromatherapy is one of the non-pharmacological methods to relax the mother in labor and is able to shorten the second stage of labor. The purpose of this study was to determine the differences in giving lavender aromatherapy to women during stage II. This research method is a quasy experimental observational study with the method of two group post test only design on 60 mothers. Analysis of data using the Mann Whitney test. The results showed that giving lavender aromatherapy in labor II can increase maternal relaxation and accelerate the duration of second stage labor.
\end{abstract}

Keywords: aromatherapy; lavender; labor; primipara 


\section{PENDAHULUAN}

Persalinan merupakan suatu proses yang alamiah. Secara fisiologis, pada ibu bersalin akan terjadi kontraksi yang menyebabkan penipisan dan pembukaan serviks. Hal ini akan menyebabkan ibu merasakan nyeri dan sering kali nyeri ini dipersepsikan sebagai pengalaman nyeri paling hebat yang pernah dirasakan oleh ibu bersalin selama hidupnya (Beigi et al., 2010)

World health Organization (WHO) memperkirakan setiap tahun terjadi 210 juta kehamilan di seluruh dunia, dan 20 juta perempuan mengalami kesakitan saat persalinan. Dalam persalinan sering kali juga timbul rasa cemas, panik, dan takut rasa sakit yang luar biasa yang dirasakan ibu yang dapat mengganggu proses persalinan dan mengakibatkan lamanya proses persalinan yang menimbulkan partus macet. Nyeri yang hebat pada proses persalinan dapat membuat ibu merasa khawatir dan cemas. Hubungan antara nyeri dan kecemasan ini bersifat kompleks dan saling mempengaruhi antara satu dan lainnya. Kecemasan dapat meningkatkan nyeri, dan nyeri juga dapat menyebabkan perasaan cemas. Ketika ibu bersalin merasa takut, cemas dan tidak dapat mentolerir rasa nyeri yang ia rasakan, maka secara spontan tubuh akan meningkatkan pelepasan hormone katekolamin yaitu epinefrin dan norepinefrin. Peningkatan hormone ini akan menyebabkan terjadinya vasokontriksi pembuluh darah sehingga dapat meningkatkan tekanan darah ibu, menurunkan aliran darah ke uterus, menurunkan aliran uteroplasenta dan menurunkan aktivitas uterus sehingga dapat menyebabkan persalinan menjadi lama. Keadaan tersebut juga memberi dampak pada pola denyut jantung janin sehingga menjadi tidak normal. Hal ini menunjukkan bahwa nyeri yang tidak teratasi selama proses persalinan dapat menyebabkan komplikasi baik bagi ibu maupun janin (Regina, 2011)

Survei Demografi dan Kesehatan Indonesia tahun 2014 mencatat bahwa partus lama $(42,96 \%)$ merupakan penyebab kematian maternal dan perinatal utama disusul oleh perdarahan 35,26\%, dan eklampsia 16,44\%. Hasil survei yang didapatkan bahwa partus lama dapat menyebabkan kegawatdaruratan pada ibu dan bayi. Pada ibu dapat terjadi perdarahan, syok, dan kematian sedangkan pada bayi dapat terjadi fetal distress, asfiksia dan caput (Kemenkes, 2014)

Partus lama rata-rata di dunia menyebabkan kematian ibu sebesar 8\% dan di Indonesia sebesar 9\%. Persalinan lama bisa mengakibatkan infeksi, kehabisan tenaga, dehidrasi, dan perdarahan post partum yang dapat menyebabkan kematian ibu. Selain berdampak pada ibu, partus lama juga berdampak pada bayi dimana janin akan mengalami infeksi, cedera dan asfiksia yang dapat meningkatkan kematian bayi (Ardhiyanti \& Susanti, 2016)

Pada kala I persalinan berkaitan dengan nyeri persalinan dimana terdapat beberapa aspek yang berkaitan dengan nyeri persalinan yang mempengaruhi proses persainan itu sendiri. Pengaruh utama yang terjadi adalah karena terpicunya sistem simpatis dimana terjadi peningkatan kadar katekolamin terutama epineprin yang dapat menyebabkan gangguan pada kontraksi (Maryunani, 2010)

Rasa nyeri pada persalinan mengakibatkan pengeluaran adrenalin yang akan mengakibatkan pembuluh darah berkontriksi sehingga akan mengurangi aliran darah yang membawa oksigen ke uterus dan mengakibatkan penurunan kontraksi uterus yang akan memperpanjang waktu persalinan (Indrayani, 2013) 
Berbagai metode untuk memperpendek durasi persalinan telah dianjurkan dan terbukti baik secara farmakologi maupun nonfarmakologi. Metode mengatasi nyeri secara farmakologi lebih efektif apabila dibandingkan dengan metode nonfarmakologi. Namun, metode farmakologi berpotensi memberikan efek samping yang kurang baik bagi ibu maupun janin. Sedangkan metode nonfarmakologi cenderung lebih mudah dan aman untuk diberikan kepada ibu bersalin. Metode nonfarmakologi tersebut antara lain adalah hipnosis, acupressure, yoga, sentuhan terapeutik, aromatherapy, relaksasi, mendengarkan musik, kompres hangat, kompres dingin dan pemberian birth ball (Bobak et al., 2012)

Aromaterapi merupakan salah satu metode nonfarmakologi untuk merelaksasi ibu bersalin. Aromatherapy adalah metode yang menggunakan minyak esensial untuk meningkatkan kesehatan fisik, emosi, dan spirit efek lainnya adalah menurunkan nyeri dan kecemasan (Monahan et al., 2007)

Aromatherapy Lavender merupakan salah satu minyak esensial analgetik yang mengandung $8 \%$ terpenadan $6 \%$ keton. Monoterpena merupakan jenis senyawa terpenayang paling sering ditemukan dalam minyak atsiri tumbuhan. (Tarsikah et al., 2012) Ekstrak lavender berkualitas tinggi tidak hanya sesuai dengan monograf ini namun idealnya melebihi spesifikasi tersebut dengan kandungan linalil asetat yang lebih tinggi (idealnya 33-45\%) dan lavandulil asetat $(\geq 1,5 \%)$, dan batas yang lebih rendah untuk kandungan cineol. yang merupakan senyawa esteryang terbentuk melalui penggabungan asam organik dan alkohol. Ester sangat berguna untuk menormalkan keadaan emosi serta keadaan tubuh yang tidak seimbang (Appleton, 2014)

Berdasarkan latar belakang diatas penulis tertarik untuk melakukan penelitian pemberian aromaterapi lavender terhadap lama persalinan kala II pada ibu primipara.

\section{METODE}

Penelitian ini merupakan penelitian observasional quasy eksperimental dengan metode two group post test only design. kelompok pertama tidak diberikan perlakuan sebagai kelompok kontrol dan kelompok kedua diberikan perlakukan berupa aromaterapi lavender. Setelah itu akan dilakukan observasi untuk menilai lama persalinan kala II pada masing-masing kelompok (M. Dahlan, 2013)

Sampel dalam penelitian ini adalah ibu bersalin dengan kriteria inklusi adalah Ibu bersalin dengan usia $\geq 20$ tahun, primigravida, Usia kehamilan aterm (37-40 minggu), Bersedia menjadi sampel. Kriteria eklusi adalah adanya komplikasi pada kehamilan dan komplikasi pada persalinan kala II.

Besar sampel dalam penelitian adalah 60 sampel yang terdiri dari 30 sampel sebagai kelompok kontrol dan 30 sampel sebagai kelompok intervensi. Pengambilan sampel penelitian sebanyak 60 orang dilakukan secara purposive sampling, klien yang akan ada pada waktu pengambilan sampel yang memenuhi kriteria inklusi dan ekslusi diambil menjadi sampel (S. Dahlan, 2010)

Pengumpulan data dilakukan selama empat bulan di dua buah Praktik Mandiri Bidan di Kota Palembang. Instrumen pengumpulan data dalam penelitian ini adalah lembar observasi persalinan. 
Pengolahan data dalam penelitian ini mencakup langkah-langkah sebagai berikut editing, coding, entry, cleaning. Untuk menilai perbedaan lama persalinan antara kelompok kontrol dan kelompok intervensi menggunakan uji Chi Square (M. Dahlan, 2013)

\section{HASIL DAN PEMBAHASAN}

Penelitian ini dilakukan terhadap 60 ibu bersalin di Praktek Mandiri Bidan (PMB) didapatkan hasil :

Tabel 1. Karakteristik Responden

\begin{tabular}{lcc}
\hline $\begin{array}{l}\text { Karakteristik } \\
\text { Responden }\end{array}$ & Frekuensi & \% \\
\hline Usia Responden & 2 & 3.3 \\
$\quad$ Dibawah 20 Tahun & 58 & 96.7 \\
20 - 35 Tahun & & \\
Pendidikan Ibu & 32 & 53.3 \\
$\quad$ SMA & 28 & 46.7 \\
PT & & \\
Pendamping Persalinan & 55 & 91.7 \\
$\quad$ Suami & 2 & 3.3 \\
Ibu/ Mertua & 3 & 5.0 \\
$\quad$ Saudara &
\end{tabular}

Hasil analisis statistik menunjukkan bahwa dari 60 responden ibu bersallin didapatkan bahwa usia responden 20-35 tahun sebanyak 58 responden (96.7\%), pendidikan ibu yaitu SMA sebanyak 32 responden (53.3\%), pendamping persalinan suami sebanyak 55 responden $(91.7 \%)$

Table 2. Distribusi Frekuensi Lama Persalinan Kala II pada Kelompok Intervensi dan Kelompok Kontrol

\begin{tabular}{lcccc}
\hline \multirow{3}{*}{ Kelompok } & \multicolumn{3}{c}{ Lama Persalinan } & \\
\cline { 2 - 4 } & $<\mathbf{3 0}$ & $\mathbf{3 0 - 6 0}$ & $\mathbf{> 6 0}$ & Total \\
& Menit & Menit & Menit & \\
\hline Intervensi & 22 & 7 & 1 & 30 \\
Kontrol & 1 & 11 & 18 & 30 \\
Total & 23 & 18 & 19 & 60 \\
\hline
\end{tabular}

Hasil analisis statistik menunjukkan bahwa dari 60 responden ibu bersallin didapatkan bahwa mayoritas responden pada kelompok intervensi 22 orang $(36,7 \%)$ memiliki lama persalinan kurang dari 30 menit.

Table 3. Perbedaan Lama Persalinan Kala II pada Kelompok Intervensi dan Kelompok Kontrol

\begin{tabular}{ccccc}
\hline \multirow{2}{*}{ Kelompok } & \multicolumn{3}{c}{ Lama Persalinan } & \\
\cline { 2 - 4 } & $\begin{array}{c}<\mathbf{3 0} \\
\text { Menit }\end{array}$ & $\begin{array}{c}\mathbf{3 0 - 6 0} \\
\text { Menit }\end{array}$ & $\begin{array}{l}>\mathbf{6 0} \\
\text { Menit }\end{array}$ & \\
\hline Intervensi & 22 & 7 & 1 & 0 \\
Kontrol & 1 & 11 & 18 & 0.000 \\
$\quad$ Total & 23 & 18 & 19 & \\
\hline
\end{tabular}


Hasil analisis statistik menunjukkan bahwa perbedaan lama persalinan kala II pada kelompok intervensi dan kelompok kontrol adalah ada perbedaan lama persalinan kala II pada kelompok intervensi dan kelompok control dengan nilai $p<0.001$.

Aromaterapi lavender terbukti efektif dalam penurunan rasa nyeri pada persalinan kala I fase aktif. Menurut penelitian sebelumnya, pada kala I fase aktif kontraksi uterus lebih sering dan kuat. Oleh karena itu, nyeri yang dirasakan semakin meningkat daripada fase laten meskipun bervariasi bagi setiap individu. Setiap respoden dalam penelitian ini berada pada fase aktif mulai dari pembukaan 4-8 cm. (Leksana, 2011)

Dilatasi serviks mempengaruhi persepsi nyeri dan kondisi psikologi yang dirasakan oleh seiap orang. Pada saat menghirup aromaterapi lavender dapat merangsang tubuh melepaskan senyawa endhorphin yang dapat menghilangkan sakit secara alamiah sehingga lebih nyaman. Responden dianjurkan untuk terus menghirup aroma terapi lavender selama proses persalinan dianjurkan agar rasa nyeri dapat semakin menurun. Hal tersebut terjadi karena sistem saraf menjadi terbiasa terhadap stimulus dan organ- organ indra berhenti merespon nyeri tersebut.(Rosalinna, 2018)

Minyak lavender adalah salah satu aromaterapi yang terkenal memiliki efek menenangkan. Penelitian yang dilakukan terhadap manusia mengenai efek aromaterapi lavender untuk relaksasi, kecemasan, mood, dan kewaspadaan pada aktivitas EEG (Electro Enchepalo Gram) menunjukkan terjadinya penurunan kecemasan, perbaikan mood, dan terjadi peningkatan kekuatan gelombang alpha dan beta pada EEG yang menunjukkan peningkatan relaksasi. Didapatkan pula hasil yaitu terjadi peningkatan secara signifikan dari kekuatan gelombang alpha di daerah frontal, yang menunjukkan terjadinya peningkatan rasa kantuk. (Yamada et al., 2005)

Penelitian sebelumnya menyatakan bahwa kandungan lavender oil terdiri dari linalool, linalyl acetate $\alpha$ - dan $\beta$ - pinenne dan 1,8- cineole sehingga mampu menurunkan secara spontan kontraksi uterus yang mengalami spasme pada otot instestinalnya. (Lis-BAlchim, 2009)

Oleh karena itu, bau yang menyenangkan akan menciptakan perasaan tenang dan senang sehingga dapat mengurangi kecemasan. Selain itu, setelah ke limbik aromaterapi menstimulasi pengeluaran enkefalin atau endorfin pada kelenjar hipothalamus, periaqueductal gray dan medula rostral ventromedial. Enkefalin merangsang daerah di otak yang disebut raphe nucleus untuk mensekresi serotonin sehingga menimbulkan efek rileks, tenang dan menurunkan kecemasan. Serotonin juga bekerja sebagai neuromodulator untuk menghambat informasi nosiseptif dalam medula spinalis. Neuromodulator ini menutup mekanisme pertahanan dengan cara menempati reseptor di kornu dorsalis sehingga menghambat pelepasan substansi $\mathrm{P}$. Penghambatan substansi $\mathrm{P}$ akan membuat impuls nyeri tidak dapat melalui neuron proyeksi, sehingga tidak dapat diteruskan pada proses yang lebih tinggi di kortek somatosensoris dan transisional (Karlina et al., 2014)

Hal ini sejalan dengan penelitian yang dilakukan oleh Janula dan Mahipal menunjukkan bahwa $65 \%$ responden pada kelaompok yang diberikan aromaterapi lavender menunjukkan bahwa hal terseut dapat membantu meringankan nyeri dan memperbaiki keadaan emosional selama proses 
persalinan. Penelitian tersebut juga diperoleh bahwa skor nyeri pada kelompok yang diberikan atomaterapi lavender dapat berguna untuk memberikan kenyamaan dan meringankan nyeri dapa ibu selama proses persalinan (Janula \& Mahipal, 2015)

Berdasarkan hasil penelitian sebelumnya, terdapat selisih rerata percepatan waktu persalinan kala II pada kelompok intervensi dan kelompok kontrol lavender. Rerata persalinan kala II dengan pemberian aromaterapi lavender yakni 64,00 menit sedangkan rerata lama persalinan kala kelompok tanpa intervensi yakni 84,00 menit. (Situmorang et al, 2019)

Aromaterapi lavender juga menurunkan tingkat kecemasan seperti hasil penelitian Arwani pada pasien sebelum operasi dengan anestesi spinal di RS Tugu Semarang (Sriningsih \& Hartono, 2013)

Pemberian aromaterapi lavender bermanfaat meningkatkan kondisi fisik dan psikologis ibu dalam masa persalinan. Untuk kondisi fisik, aromaterapi lavender dapat menurunkan rasa nyeri, sedangkan untuk kondisi psikologis, aromaterapi lavender dapat merelaksasi pikiran, menurunkan kecemasan pada ibu yang akan menghadapi proses persalinan. Sehingga para ibu hamil memiliki tenaga yang adekuat untuk mengejan dalam proses persalinannya (Sharma, 2009)

Menurut asumsi peneliti, penerapan aromaterapi lavender pada proses persalinan berpengaruh terhadap tingkat nyeri persalinan. Ibu yang diberikan aromaterapi lavender pada proses persalinan mengalami tingkat nyeri persalinan yang rendah dibandingkan dengan ibu yang tidak diberikan aromaterapi lavender pada proses persalinan. Aromaterapi lavender dapat mengurangi rasa cemas serta ketakutan menjelang persalinan yang dapat menyebabkan ketegangan, rasa nyeri, dan sakit saat persalinan, dan mampu mengontrol sensai rasa sakit pada saat kontraksi rahim, serta meningkatkan kadar endorfin dan epinerfin dalam tubuh untuk mengurangi rasa nyeri pada saat kontraksi dalam persalinan.

\section{SIMPULAN}

Berdasarkan hasil penelitian dapat disimpulkan bahwa pemberian aromaterapi lavender pada persalinan dapat membantu proses persalinan Kala II.

\section{DAFTAR PUSTAKA}

Appleton, B. J. (2014). Lavender Oil for Anxiety and Depression. February 2012, $1-8$.

Ardhiyanti, Y., \& Susanti, S. (2016). Factors of The Mother Related to Obstructed Labour Case at RSUD Arifin Achmad Pekanbaru. Jurnal Kesehatan Komunitas, 3(2), 83-87. https://doi.org/https://doi.org/10.25311/keskom.Vol3.Iss2.108

Beigi, N., Broumandfar, K., \& Abedi, H. (2010). Women's experience of pain during childbirth. Iranian Journal of Nursing and Midwifery Research, 15(2), 77-82. https://www.ncbi.nlm.nih.gov/pmc/articles/PMC3093177/

Bobak, Lowdermilk, \& Jense. (2012). Buku Ajar Keperawatan Maternitas. EGC. 
Dahlan, M. (2013). Statistik Untuk Kedokteran Kesehatan. Salemba Medika.

Dahlan, S. (2010). Besar Sampel dan Cara Pengambilan Sampel dalam Penelitian Kedokteran dan Kesehatan (3 (ed.)). Salemba Medika.

Indrayani, D. (2013). Asuhan Persalinan dan bayi Baru Lahir. CV. Trans Info Media.

Janula, R., \& Mahipal, S. (2015). Effectiveness of aromatherapy and biofeedback in promotion of labour outcome during childbirth among primigravidas. Health Science Journal, 9(1), 1-5.

Karlina, S., Reksohusodo, S., \& Widayati, A. (2014). Pengaruh Pemberian Aromaterapi Lavender secara Inhalasi terhadap Penurunan Intensitas Nyeri Persalinan Fisiologis pada Primipara Inpartu Kala Satu Fase Aktif di BPM "Fetty Fathiyah" Kota Mataram. Fakultas Kedokteran Universitas Brawijaya, 108-119.

Kemenkes. (2014). Survei Demografi dan Kesehatan Indonesia tahun 2014.

Leksana, E. (2011). Mengatasi Nyeri Persalinan. CDK, 38(4).

Lis-Balchim, M. (2009) Aromateraphy Science a Guide For Healthcare Profesionals. Londom Pharmaceutical Press

Maryunani, A. (2010). Ilmu Kesehatan Anak. CV. Trans Info Media.

Monahan, F. ., Neighbors, M., Sands, J. K., Marek, J. ., \& Green, C. . J. (2007). Phipps' medicalsurgical nursing: Health and illness perspectives (8th ed.). Mosby Inc.

Regina, N. (2011). Asuhan Keperawatan Maternitas. Ghalia Indonesia.

Rosalinna. (2018). Pengaruh Pemberian Aromaterapi Lavender Terhadap Pengurangan Rasa Nyeri Pada Persalinan Kala I di Wilayah Puskesmas Klego I Boyolali. Jurnal Publikasi Kebidanan, 9, 1-10.

Sharma ,S. (2009) Aroma Terapi. Karisma

Situmorang, C., Losu, FN., Pratiwi, D. (2019) Pengaruh Aromaterapi Lavender Terhadap Percepatan Persalinan pada Ibu Primipara di RSUD Selebesolu Kota Sorong. Jurnal Ilmiah Bidan, 7 (1)

Sriningsih, I., \& Hartono, R. (2013). Pengaruh Pemberian Aromaterapi Terhadap Tingkat Kecemasan Pasien Sebelum Operasi Dengan Anestesi Spinal Di Rs Tugu Semarang. Link, 1, 83-87.

Tarsikah, Susanto, H., \& Sastramihardja, H. S. (2012). Penurunan Nyeri Persalinan Primigravida Kala I Fase Aktif Pascapenghirupan Aromaterapi Lavender. Majalah Kedokteran Bandung, 44(1), 19-26. 
https://doi.org/10.15395/mkb.v44n1.210

Yamada, K., Mimaki, Y., \& Sashida, Y. (2005). Effects of inhaling the vapor of Lavandula burnatii super-derived essential oil and linalool on plasma adrenocorticotropic hormone (ACTH), catecholamine and gonadotropin levels in experimental menopausal female rats. Biological and Pharmaceutical Bulletin, 28(2), 378-379. https://doi.org/10.1248/bpb.28.378 